\author{
Marquette University \\ e-Publications@Marquette
}

College of Professional Studies Faculty

Research and Publications

Professional Studies, College of

2012

\title{
A Method to Assess the Organizing Behaviors Used in Physicians' Counseling of Standardized Parents after Newborn Genetic Screening
}

\author{
Stephanie A. Christopher \\ Marquette University, stephanie.christopher@marquette.edu \\ Nadia Y. Ahmad \\ Medical College of Wisconsin \\ Lisa Bradford \\ Medical College of Wisconsin \\ Jenelle Collins \\ Medical College of Wisconsin \\ Kerry L. Eskra \\ Medical College of Wisconsin
}

See next page for additional authors

Follow this and additional works at: https://epublications.marquette.edu/cps_fac

Part of the Medicine and Health Sciences Commons

\section{Recommended Citation}

Christopher, Stephanie A.; Ahmad, Nadia Y.; Bradford, Lisa; Collins, Jenelle; Eskra, Kerry L.; Kirschner, Alison La Pean; O'Tool, Faith O.; Roedl, Sara J.; and Farrell, Michael H., "A Method to Assess the Organizing Behaviors Used in Physicians' Counseling of Standardized Parents after Newborn Genetic Screening" (2012). College of Professional Studies Faculty Research and Publications. 30.

https://epublications.marquette.edu/cps_fac/30 


\section{Authors}

Stephanie A. Christopher, Nadia Y. Ahmad, Lisa Bradford, Jenelle Collins, Kerry L. Eskra, Alison La Pean Kirschner, Faith O. O'Tool, Sara J. Roedl, and Michael H. Farrell 
Volume 9(2) (2012), 101-111

Copyright (c) Equinox Publishing Ltd

Sheffield

http://equinoxpub.com

DOI: $10.1558 /$ cam.v9i2.101

\title{
A method to assess the organizing behaviors used in physicians' counseling of standardized parents after newborn genetic screening
}

\author{
STEPHANIE A. CHRISTOPHER ${ }^{1,2}$, NADIA Y. AHMAD ${ }^{1}$, LISA BRADFORD ${ }^{1}$, JENELLE L. COLLINS ${ }^{1}$, \\ KERRY ESKRA ${ }^{1}$, ALISON LA PEAN KIRSCHNER ${ }^{1}$, FAITH O. O'TOOL ${ }^{1}$, SARA J. ROEDL ${ }^{1}$ AND \\ MICHAEL H. FARRELL ${ }^{1}$
}

(1) Medical College of Wisconsin, Milwaukee, USA (2) Marquette University, Milwaukee, USA

\begin{abstract}
Well-organized conversation can improve people's ability to comprehend and retain information. As part of a long-term effort to adapt Quality Improvement techniques for communication, we developed an explicit-criteria method to assess usage of three organizing behaviors (OBs): 'opening behaviors' to establish goals; 'structuring behaviors' to guide patients through conversation; and 'emphasizing behaviors' that signal a need for attention. Pairs of abstractors independently reviewed transcripts in a demonstration sample of conversations between physicians and standardized parents after newborn screening identifies carrier status for sickle cell disease. Criteria for at least one $O B$ were identified in 50/84 transcripts (60\%), including 27 with at least one opening behavior (32\%), 5 with at least one structuring behavior (6\%), and 38 with at least one emphasizing behavior (45\%). The limited number of OBs raises concern about communication after newborn screening. Assessment and improvement of $O B$ usage may improve understanding and allow parents to more actively participate in health care.
\end{abstract}

Keywords: communication methods; newborn genetic screening; physician-patient communication; quality improvement

\section{Introduction}

Organization is an important component of effective communication in health care, patient education, and in everyday conversations. The way in which speech is organized influences the degree to which audiences comprehend and retain verbal information, which may have significant implications for health care and patient education (Lucas 2001). Organized speech helps audience members to be active listeners and incorporate new information into growing mental models (Seel 2006), as well as use the new information in subsequent decision-making (Chesebro and McCroskey 2001; Thompson 1960; Titsworth 2001). Well-organized speech can also make the speaker appear more credible in the eyes of the audience (Sharp Jr and McClung 1966). When information is complicated, organization may help patients with the mental demands of simultaneously processing new information, experiencing emotions, and holding several unfamiliar concepts in mind (Morgan et al. 2001; Seel 2006). In contrast, disorganized speech may lead to confusion, recall problems, annoyance, or problems with the patient-provider relationship (Thompson 1960).

Although organization has been a key focus in the fields of communication and public speaking, it has not been a well-developed focus in the field of health care communication. This is unfortunate, as health care is full of highly complicated and emotionally loaded messages, many of which can have important consequences for health, well-being, and family relationships. Much of our research focuses on communication between health care providers and parents after newborn screening (NBS). Nearly every infant in the United States is screened shortly after birth for a panel of life-threatening diseases, in order to facilitate early treatment and reduce morbidity and mortality (Allen and Farrell 1996). Commonly screened diseases include sickle cell anemia, a blood disease common among African Americans, and cystic fibrosis, a lung and nutritional disease common among Caucasians but also found in other ethnic groups. When screening for genetic diseases, communication is especially 
important because most abnormal results are for infants with heterozygous or 'carrier' status, a complex idea to convey to nervous parents.

This paper is part of a long-term project to develop affordable methods for assessing and improving the 'quality' of communication services provided to parents after newborn screening. Communication effectiveness in general is associated with patients' comprehension, adherence to recommended treatments, and satisfaction with care, as well as with improvement in their symptoms, outcomes, and emotional states (Cegala et al. 2000; DiMatteo et al. 1986; Elwyn et al. 2000; Greene et al. 1994; Hall et al. 1988; Inui et al. 1976; Kaplan et al. 1989; Levinson and Roter 1993; Orth et al. 1987; Robbins et al. 1993; Rost et al. 1991; Street Jr 1991). Primary care providers' communication about newborn screening has been criticized by families and public health officials because of problems like bad timing, inadequate content, and poor conduct (Ciske et al. 2001; M. H. Farrell et al. 2001).

This paper on providers' use of organizing behaviors $(\mathrm{OBs})$ in communication after newborn screening is one of several that demonstrate 'communication quality indicators'. Quality indicators are quantitative, targeted variables about communication behaviors that use techniques adapted from Quality Improvement for assessment of health care on a population scale, that is, across large geographic regions. In contrast, most health care communication efforts have focused on educating individual physicians in a single institution. For example, our other communication quality indicators quantify physicians' use and timing of certain content messages (M. H. Farrell et al. 2009a; M. H. Farrell et al.2005; La Pean and Farrell 2005), physicians' use of jargon and explanations (Deuster et al. 2008; M. Farrell et al. 2008), and assessment of understanding (M. H. Farrell and Kuruvilla 2008; M. H. Farrell et al. 2009b). Much of this prior work was done with convenience samples of physicians still in residency training programs, but to study use of organizing behaviors we decided to collect a sample of more experienced physicians who have graduated from residency at least two years before the time of the study.
The purpose of this study was to develop the method for reliably assessing the use of organizing behaviors in such a way that the method could be used across an entire population of physicians. Thus, the method needs to be efficient and reliable so that it can be used by abstractors trained for quality improvement, rather than health care providers or faculty members. Once population-scale methods for communication quality assurance have been demonstrated for communication after newborn screening, similar programs may be developed to address many other communication problems in health care.

\section{Methods}

\subsection{Development of OB taxonomy}

To identify a variety of OBs for our quality indicator measures, we performed a broad review of the literature and guidelines on health care communication and public speaking (Baile et al. 2000; Chesebro and McCroskey 2001; Coulehan and Block 2006; Fujishin 2008; Kurtz et al. 1998; Ley 1988; Lipkin et al. 1995; Lucas 2001; Makoul 2001; Morgan et al. 2001; Roter and Hall 1992; Sharp Jr and McClung 1966; Silverman et al. 1998; Smith 2002; Titsworth 2001). We found many overlapping variants of behaviors meant to organize communication and grouped them for measurement purposes into three categories: opening behaviors, structuring behaviors and importance emphasis (Table 1). These OBs have not been specifically studied in a health care context, but they have long been described in communication studies outside of health care. Many of the OBs take advantage of a cognitive process called the 'serial position' effect, which refers to the effect of position of a piece of information and its ability to impact listener recall. Specifically, primacy and recency impact people's ability to remember concepts presented at the beginning or end of a collection or series of concepts (Glanzer and Cunitz 1966; Ley et al. 1973).

Table 1. Organizing behavior categories

\begin{tabular}{|l|l|}
\hline Organizing behavior & Definition \\
\hline Opening behaviors & $\begin{array}{l}\text { Statement in which the speaker establishes goals for a conversation, or indicates that a } \\
\text { single, specific content message will be the topic of conversation. }\end{array}$ \\
\hline Structuring behaviors & $\begin{array}{l}\text { Statements that guide the patient through conversation, typically by providing a list of spe- } \\
\text { cific content areas to be covered in the future (outline), the past (summary), or as progress } \\
\text { is made through conversation (signposting). }\end{array}$ \\
\hline Importance emphasis & $\begin{array}{l}\text { A signal that the patient should pay close attention or otherwise remember a certain } \\
\text { statement. }\end{array}$ \\
\hline
\end{tabular}

\section{equinoxonline}




\subsubsection{Opening behaviors}

Our first category of OBs includes several techniques for establishing the goals of an upcoming conversation. A simple version of an opening behavior occurs when a provider asks a patient about his or her chief complaint. An open-ended query may be more useful than a close-ended or leading question (Coulehan and Block 2006; Kurtz et al. 1998; Lipkin et al. 1995; Makoul 2001; Morgan et al. 2001; Roter and Hall 1992; Silverman et al. 1998; Smith 2002). When patients were asked a general query such as 'What can I do for you today?' they often gave a longer and more detailed response than patients who were asked a confirmatory question like 'I understand you are having some sinus problems today?' (Heritage and Robinson 2006).

Other types of OBs included in this group were headline statements and the so-called 'warning shot'. Headline statements are useful for purpose-driven conversations like the ones in this study, in which a provider may specify a main topic for conversation, or seek to highlight a main message. In many cases, the headline includes an explicit declaration of purpose like 'I asked you here because...' or 'I have a lot of complicated information to talk about'.

The warning shot behavior is recommended for conversations involving bad news, in order to help reduce shock, gauge the patient's initial response, or focus the patient's subsequent attention (Baile et al. 2000; Maynard 1996). For example, physicians may say, 'I'm afraid I have some concerning news'.

A more interactive opening behavior is found in the 'agenda setting' technique, in which the provider asks the patient to identify his or her complaints and goals, one by one, and then negotiates priority for these topics versus the provider's goals (Smith 2002). When providers interrupt a patient before the patient is able to list all the concern, then the patient's main concerns may only be raised in the last few minutes of the appointment (the so-called 'doorknob complaints') (Marvel et al. 1999; Rhoades et al. 2001).

\subsubsection{Structuring behaviors}

The structuring behaviors group is composed of three variant OBs that we originally had considered to be separate behaviors: outlining, summarizing, and signposting. These variants serve to facilitate understanding by providing a framework to guide the patient through the conversation. For example, ordering lists of messages in a hierarchical manner is associated with two to three-fold better recall than when messages are presented in random order (Bower et al. 1969). Ley, Bradshaw, Eaves and Walker found that relaying information in 'labeled categories' (e.g. informing participants what kind of information they would be told and in what order) also increased recall among medical patients and healthy volunteers (Ley et al. 1973). We combined the three variants during pilot testing because many statements tended to meet criteria for more than one of the variants.

An outline early in conversation provides a list of topics or messages to be covered. Outlining may help patients to prepare for concepts as they arise, and place complicated messages in context with each other.

A summary near the end of conversation lists topics or messages that were covered, which may help to reinforce learning or remind the patient.

'Signposting' (Lucas 2001) refers to guidance a physician might provide about progress through a conversation. For example, a speaker might list topics already discussed ('So far we have talked about " $X$ " and "Y") and then mention the topic about to arise ("now we will talk about "Z"').

\subsubsection{Importance emphasis}

Our third category of OBs is called importance emphasis, referring to explicit statements that the patient should pay close attention or remember a specific message. For example, a physician may comment, 'the most important thing for you to know is...' or 'The bottom line is....' Importance emphasis may be especially useful in increasing understanding of concepts presented in the middle of a list of things to be learned, when many errors in recall may occur (DuBois et al. 1979).

\subsection{Development of an explicit-criteria data dictionary}

We developed an explicit-criteria data dictionary to adapt our findings from the literature review into an instrument for abstractors to use for producing communication quality indicator data from transcripts. Explicit-criteria data dictionaries define quality indicators using very detailed instructions and extensive examples, in order to minimize the need for reviewers to use subjective judgment (Allison et al. 2000; Ashton et al. 1999). The final version of data dictionary for this analysis included criteria for definite and partial versions of the three categories described in the methods section, derived over reiterative discussions between authors and pilot testing with a small number of randomly selected transcripts.

The dictionary and resulting communication quality indicator instrument followed our usual

\section{equinoxonline}


approach of using a trichotomous scheme (definite / partial / absent) to account for differences between clear examples of a behavior and statements that did not meet the full definition but demonstrated a clear attempt at opening, structuring, or importance emphasis (Deuster et al. 2008; M. Farrell et al. 2008; M. H. Farrell et al. 2009a and 2009b; M. H. Farrell and Kuruvilla 2008). For example, the statement 'We have some things to talk about' was classified as an OB-1 partial, because it opened the conversation but lacked specific details about the topic of the conversation. The statement 'It's just something you need to be aware of' was classified as an OB-3 partial because it attempted to call attention to a piece of information but used indirect wording and the word 'just' to soften the effect.

\subsection{Participants and data collection}

To demonstrate use of the OB communication quality indicator, we analyzed data from a larger study of conversations by physicians practicing outside of academic settings. During this project we recruited three parallel samples of physicians who provide primary care to newborns: 37 pediatricians in Connecticut, 16 pediatricians in Wisconsin, and 31 family physicians in Wisconsin (final $\mathrm{N}=84$ ). We reasoned that using the three samples would ensure that participants came from different training programs, and thus would have differing communication training.

Participating physicians' names and contact information were obtained from a search of the American Medical Association (AMA) Masterfile for providers who were reported working in direct patient care, had graduated from residency at least 2 years before, offered direct patient care, and had an office located in a 40 mile radius around our institutions.

Identified physicians were contacted by telephone and invited to participate at a time of their convenience. Physicians who participated listened to a brief clinical vignette about an infant found to have $\mathrm{SCH}$ trait status, and were asked to provide initial counseling about the abnormal results to a standardized patient posing as the infant's mother. Participants were offered $\$ 20$ as gratuity for their participation, and were paid via traveler's check (Connecticut) or gift certificate (Wisconsin).

\subsection{Standardized Parent Encounter}

The transcripts analyzed in the project were of a physician counseling a standardized parent about the results of an abnormal newborn screening result. All standardized patients were women and chosen to plausibly depict the age and ethnicity of a mother of an infant with $\mathrm{SCH}$. Encounters began with a simple question: 'Hello, doctor. I heard you wanted to speak with me, something about my baby's screening test result?'

The standardized parents were coached to adopt a neutral facial expression and to avoid any appearance of anxiety or other emotions. These instructions helped our analysis to focus on organizing behaviors rather than on the physicians' ability to respond to apparent confusion. The standardized parents were also coached to appear calm and to avoid any appearance of confusion. These instructions helped to eliminate variability between patient responses, in order to facilitate comparability across physicians. The standardized parents did not improvise or interject any comments during the counseling session, to maintain uniformity of subsequent transcripts for analysis. If there was a pause in conversation, the standardized parents used a neutral continuer, such as 'uh-huh'.

Recordings were transcribed, proofread for accuracy by a board-certified pediatrician, and stripped of identifying information.

\subsection{Abstraction and analyses}

To facilitate abstraction, we used a sentence diagramming procedure to parse physician speech into individual 'statements', each of which contained one subject and one predicate. The statements also allowed us to calculate timing of OBs, relative placement in conversation, and the number of concepts raised between OBs and content messages.

Two of nine independent abstractors were instructed to read each transcript statement by statement, comparing the text in the statement with entries in the explicit-criteria data dictionary. If a given statement seemed to meet criteria for more than one of the OB types, abstractors were instructed to declare opening behaviors over structuring behaviors, and both opening and structuring behaviors over importance emphases.

Abstraction data were collected using our selfdeveloped software application, Transcript Abstraction System (TAS). TAS was modeled after the programs used by medical record reviewers in traditional Quality Improvement projects (Mainz 2003), allowing abstractors to read through transcripts statement by statement and to enter statement-specific data for each quality indicator.

Discrepancies between abstractor data were automatically resolved by a spreadsheet algorithm to avoid introduction of a third abstractor's subjective

\section{eevinoxonline}


judgment. As with some of our previous studies (Deuster et al. 2008; M. Farrell et al. 2008; M. H. Farrell et al. 2009a and 2009b; M. H. Farrell and Kuruvilla 2008) this algorithm allowed for merging of 'definite' and 'absent' values into a 'partial' state when an OB was not clear enough to be apparent to two abstractors. The algorithm resulted in a final status of 'definite' if the individual abstractors had entered definite, or if one had entered definite and the other entered partial. The algorithm resulted in a final status of 'partial' for all other combinations of abstractor entries except if both statements had been left blank or deliberately entered as 'absent'.

All transcripts were abstracted by two authors to assess inter-abstractor reliability. One third of abstractions were discussed afterwards to ensure quality control and consistency, following the suggestion by Feinstein (1985). Inter-abstractor reliability was calculated before merging or consensus using Cohen's kappa.

Calculations and statistical analyses were performed using Excel (Microsoft Corp., Redmond, WA) and JMP software (SAS Institute, Cary, NC). The Chi-squared test and the Wilcoxon rank sum test were used as appropriate for the type of variables being analyzed.

\section{Results}

Information about the combined participant sample is shown in Table 2.

Table 2. Participant characteristics

\begin{tabular}{lcc}
\hline Characteristics & \multicolumn{2}{c}{ No. responding } \\
& $\boldsymbol{n}$ & (\%) \\
\hline Specialty & 31 & 36.9 \\
Family medicine & 53 & 63.1 \\
Pediatrics & & \\
Gender & 57 & 67.9 \\
Male & 27 & 32.1 \\
Female & & \\
Age (years) & 38 & 45.2 \\
Less than 45 & 38 & 45.2 \\
45-65 & 8 & 9.5 \\
Greater than 65 & & \\
Years since graduation & 25 & 29.8 \\
10 years or less & 39 & 46.4 \\
11-30 & 20 & 23.8 \\
Greater than 30 & & \\
\hline
\end{tabular}

Across the 84 transcripts in the sample, definite criteria were identified for a total of 139 OBs, including 34 opening behaviors, 6 structuring behaviors, and 99 importance emphases. The inter-abstractor agreement for identification of OBs was $99 \%$, but OBs were rare enough in the sample that the Cohen's $\kappa$ (which corrects for coder matches due to chance) was 0.70 , in an acceptable range for a demonstration project.

Overall, 50 of the 84 transcripts (60\%) met definite criteria for at least one of the OB types that we had identified in our literature review. As shown in Figure 1 , abstractors identified definite criteria for two of the three types of OBs in $24 \%$ of the transcripts. Another $36 \%$ of the transcripts met definite criteria for one of the OB types. None of the transcripts contained all three types of OBs.

Figure 1. Number of organizing behavior types included in physicians' conversation

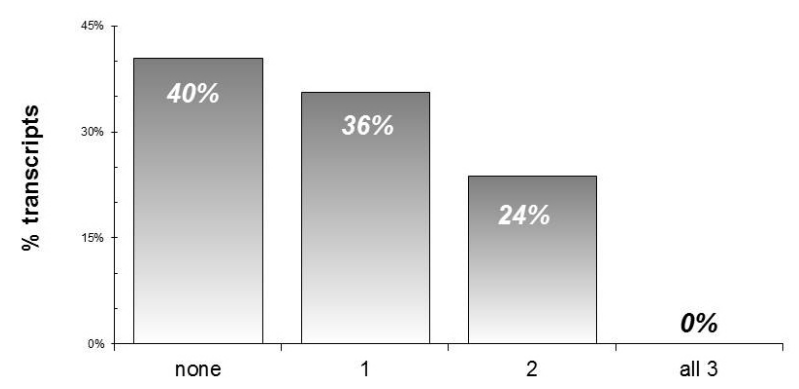

Physicians who included at least one $\mathrm{OB}$ were more likely to be younger in age (Wilcoxon $p=0.023$ ). They were also more likely to have graduated more recently from medical school (Wilcoxon $p=0.019$ ), although this factor will not be reported separately in the rest of the paper due to an $p=0.97$ Spearman correlation. There were no apparent differences in the overall use of OBs by physicians' gender (59.3\% for females, $59.7 \%$ for males).

\subsection{Providers' use of different types of $\mathrm{OBs}$}

Definite criteria for at least one opening behavior was found in 27/84 transcripts (32.1\%). Physicians were more likely to include an opening behavior if they were female ( $52 \%$ versus $25 \%$ male, $\chi^{2} p=.01$ ) or if they were younger in age (Wilcoxon $p=0.009$ ).

Structuring behaviors were rare in the sample, with only five transcripts (6\%) meeting definite criteria for at least one. We could not detect any difference in use of structuring behavior by physician gender, age, or years since graduation.

Inclusion of importance emphasis was more common than either of the other OB types. Abstractors

\section{eevinoxonline}


identified definite criteria for at least one importance emphasis in 38/84 transcripts (45.2\%). We could not detect any difference in the importance emphasis OB by physician gender, age or years since graduation.

Physicians who included an opening behavior were more likely to have included an importance emphasis, and vice versa $\left(\kappa=0.24, \chi^{2} p=0.013\right)$.

\subsection{Effect of using partial abstraction criteria}

When abstractors' partial ratings were also counted, 432 additional OB 'attempts' were identified. Over the entire sample, when partial criteria were included, an additional 32 transcripts (38\%) were found to include at least one $\mathrm{OB}$, for a total of $82 / 84$ transcripts (97.6\%). Figure 2 depicts the number of $\mathrm{OB}$ types present in transcripts when partial criteria were counted.

Figure 2. Effect of including partial criteria on number of organizing behavior types in physicians' conversations

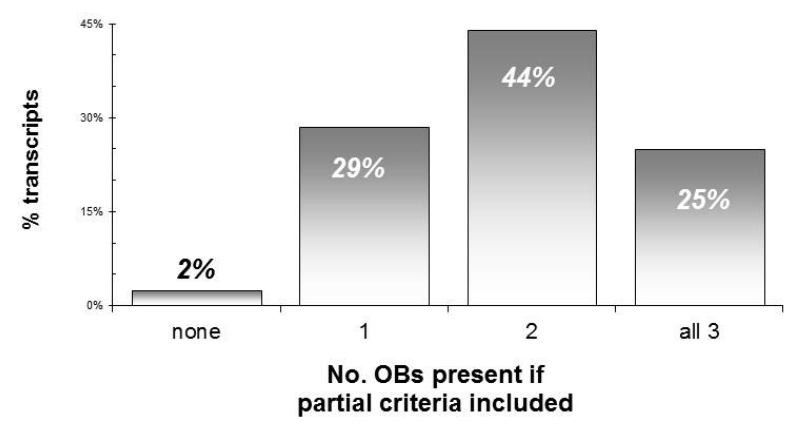

Partial-criteria importance emphases were the most common with a total of 324 identified across the entire sample. An example of a partial importance emphasis is an emphasis statement with some lessening word such as 'It's just something you need to be aware of'. The number of individual transcripts containing at least one importance emphasis increased from 38 to 79 when including partials $(94.1 \%$ of the 84 transcripts).

Partial-criteria versions of the opening behavior and structuring behavior groups were also seen. When partial criteria were included, the number of transcripts with at least one opening behavior increased from 27 to 52 (total 61.9\%), and the number of transcripts with at least one structuring behavior increased from 5 to 30 (total 35.7\%).

\subsection{Timing of $O B$ use in conversation}

Previous analyses have examined the timing of certain communication behaviors (M. H. Farrell et al. 2009b; M. H. Farrell et al. 2005; La Pean and Farrell 2005) because the effectiveness of the behaviors may vary depending on when they are included. For example, outlining at the beginning of conversation or placing emphasis at the end may help physicians to take advantage of the serial positioning effect (Glanzer and Cunitz 1966; Ley et al. 1973).

To analyze OB timing in this sample we divided each transcript into quarters using its number of statements (see methods section). We decided to analyze both definite- and partial-criteria OBs because of the large number of the latter. The numbers of the three OB types (definite- and partialcriteria) are listed in Table 3 for each of the four quarters of the transcripts. As expected, $78 \%$ of the opening behaviors were found in the first quarter of conversation, and $11 \%$ were found in the second quarter. The small number of structuring behaviors seemed to be dispersed evenly across the transcripts. Most of the importance emphases were included later in the transcripts.

Table 3. Timing of $O B$ types (definite-criteria and partialcriteria included)

\begin{tabular}{|l|rr|rr|rr|}
\hline $\begin{array}{l}\text { Quarters (of } \\
\text { the transcript) }\end{array}$ & \multicolumn{2}{|c|}{ Opening } & \multicolumn{2}{|c|}{ Structuring } & \multicolumn{2}{|c|}{ Importance } \\
behavior & \multicolumn{2}{|c|}{ behavior } & \multicolumn{2}{|c|}{ emphasis } \\
& n & (\%) & n & (\%) & n & (\%) \\
\hline 1st & 79 & $(78)$ & 15 & $(28)$ & 26 & $(6)$ \\
2nd & 11 & $(11)$ & 14 & $(26)$ & 101 & $(24)$ \\
3rd & 9 & $(9)$ & 15 & $(28)$ & 147 & $(36)$ \\
4th & 3 & (3) & 10 & $(18)$ & 141 & $(34)$ \\
\hline
\end{tabular}

\section{Discussion}

The purpose of this study was to develop a method to examine the use of organizing behaviors by experienced physicians outside of academic medical centers, and was part of our long-term effort to assess the quality of communication likely to be experienced by parents after their infants are found to have an abnormal result. Communication is an important part of the newborn screening process (M. H. Farrell and Farrell 2003), and appropriate use of OBs may improve physician communication and in doing so help parents to better understand screening results.

Organizing behaviors are one facet of the communication quality indicator panel and should be considered with our other indicators: inclusion and timing of content messages (M. H. Farrell et al. 2005; La Pean and Farrell 2005), jargon and explanations (Deuster et al. 2008; M. Farrell et al. 2008), assessments of understanding (M. H. Farrell and Kuruvilla 
2008; M. H. Farrell et al. 2009b) and assessment of emotional reactions (M. H. Farrell et al. 2012). The use of several, varied communication quality indicators in a broad panel may allow researchers and quality assessors to approach the complex concept of communication 'quality'. As with the use of quality indicators in traditional Quality Improvement, analyses can then account for specific behaviors or for high performance in one area but not in another.

The inclusion of OBs by physicians in the study was somewhat variable, even though the physicians in this sample had more experience than in our previous samples of residents (Deuster et al. 2008; M. Farrell et al. 2008; M. H. Farrell et al. 2009a and 2009b; M. H. Farrell and Kuruvilla 2008; M. H. Farrell et al. 2005; M. H. Farrell et al. 2012; La Pean and Farrell 2005). Though the use of OBs was not consistent, we were encouraged that many physicians seemed to be attempting to use at least one $\mathrm{OB}$ in counseling. We interpret the larger number of partial-criteria OBs as a sign that many physicians may recognize the importance of organization for patient understanding, even if they lack skill in effective use of OBs. Indeed, our finding that younger physicians included more definite-criteria OBs than their older colleagues may be consistent with the past two decades' greater emphasis on communication training. It is worth noting that the number of opening behaviors might have been low for this sample because of the artificial nature of the counseling task. It is also worth noting that perhaps physicians did not use the behaviors, specifically the structuring behavior (OB-2) because they did not deem the behavior useful in this context. Regardless of these factors, however, the overall scarcity of OBs seems to underscore both a need for increased teaching about OBs during medical training and a need for increased attention to communication quality after graduation.

Developing an explicit-criteria data dictionary for analyzing OBs was somewhat more of a challenge than we had experienced with our previous analyses of content messages (M. H. Farrell et al. 2005; La Pean and Farrell 2005), jargon (Deuster et al. 2008; M. Farrell et al. 2008), and assessment of understanding (M. H. Farrell and Kuruvilla 2008; M. H. Farrell et al. $2009 \mathrm{~b})$. One reason why our inter-abstractor reliability may have been less robust than for other studies could be that $\mathrm{OB}$ usage was rare, which increases the effect of correction for chance. We are also interested in exploring use of more detailed examples in the data dictionary, which may help to address crosscategory overlap inherent to the OB construct. Future research with our statewide sample of primary care providers of actual infants with $\mathrm{SCH}$ trait is focusing on improving reliability and incorporation of the $\mathrm{OB}$ communication quality indicator into prospective interventions (M. H. Farrell et al. 2011).

\subsection{Limitations}

This analysis was limited by its small sample size and in future projects we will apply this method to a larger population. Qualitative methods might have provided a richer description of organizing strategies within a two-way dialog, but qualitative methods have limited reliability and would be prohibitively expensive for use in population-scale quality improvement projects. There may be other indicators of organizing behaviors that we could not integrate into this simplified, quality-improvement approach. We adapted our quantitative, somewhat reductionist, approach of using quality indicators from Quality Improvement (Deuster et al. 2008; M. Farrell et al. 2008; M. H. Farrell et al. 2009; M. H. Farrell and Kuruvilla 2008; M. H. Farrell et al. 2005; M. H. Farrell et al. 2012; La Pean and Farrell 2005) because of that field's track record for changing physician behavior across entire geographic regions (Jencks et al. 2003). This population scale approach is most effective because physicians can develop communication problems long after training and far away from the academic centers where many received training in communication.

Another potential limitation is the use of standardized patients instead of real patients, although we see this as a benefit for population-scale efforts because it avoids logistical and privacy difficulties that would make quality improvement activities difficult. Simulation allows an equal-footing comparison that would be impossible with real patients because of variations across actual patients. Simulation is also useful because a sense of observation prompts physicians to perform as well as they are can; the resulting competence data suggests a likely ceiling for the physician's processes of communication because competence is necessary but not sufficient for real-world performance (Miller 1990). We realize, however, that physicians may wish to change their communication behavior in response to patients' or parents' reactions during the actual counseling session. In the future, we hope to use these communication quality measures with transcripts of actual physician-patient encounters.

\subsection{Implications}

The limitations notwithstanding, we see three implications of the method developed for this project. First, given the literature available on how

\section{eevinoxonline}


the placement of messages can potentially impact patient understanding (Bower et al. 1969; DuBois et al. 1979; Ley et al. 1973), it is reasonable to consider that the use of communication strategies like OBs may be associated with greater effectiveness of communication after newborn screening, and potentially with improvements in parents' understanding and psychosocial outcomes. Individual providers should be aware of the potential importance of organization, but also conscious of the likelihood that they, like the physicians in this sample, may not be using OBs as optimally as they should.

Second, if our findings about OB use are generalizable, then we may have identified one of the factors that contribute to parents' misunderstandings of physician counseling. We hope that this study will prompt greater examination of the use of OBs in training programs for communication skills. Future research will also examine the role of the timing of the organizing behaviors. Behaviors were evenly dispersed in this sample and future research will consider the effectiveness of these behaviors in relation to placement in the conversation.

In the future, we plan to continue assessment of how communication behaviors affect parent outcomes and perhaps incorporate OBs into our growing, population-scale method toolkit for assessing and improving physician communication quality. We are in the process of collecting data for a comparison study in which we will be able to compare physician communication quality indicator data, including OBs, and parent reported outcomes of anxiety and understanding of results. Though there are many studies which suggest a link between subjective assessments of physician communication and positive patient outcomes (Cegala et al. 2000; Clever et al. 2008; Kaplan et al. 1989; Ong et al. 1995; Stewart et al. 2000), the ultimate goal of this body of research is to demonstrate a method for reliably assessing discrete physician behaviors that make a profound difference in parent and patient understanding.

\section{Acknowledgement}

This project was funded by NIH grants K01-HL072530 and R01-HL086691.

\section{References}

Allen, D. B. and Farrell, P. M. (1996) Newborn screening: Principles and practice. Advances in Pediatrics 43: 231-270.
Allison, J., Wall, T., Spettell, C., Calhoun, J., Fargason, C. J., Kobylinski, R., Farmer, R. and Kiefe, C. (2000) The art and science of chart review. Joint Commission Journal on Quality Improvement 26 (3): 115-136.

Ashton, C. M., Kuykendall, D. H., Johnson, M. L. and Wray, N. P. (1999) An empirical assessment of the validity of explicit and implicit process-of-care criteria for quality assessment. Medical Care 37 (8): 798-808. http://dx.doi. org/10.1097/00005650-199908000-00009

Baile, W. F., Buckman, R., Lenzi, R., Glober, G., Beale, E. A. and Kudelka, A. P. (2000) SPIKES-A six-step protocol for delivering bad news: Application to the patient with cancer. Oncologist 5 (4): 302-311. http://dx.doi.org/ 10.1634/theoncologist.5-4-302

Bower, G. M., Clark, M. C., Lesgold, A. M. and Winzenz, D. (1969) Hierarchial retrieval schemes in recall of categorized word lists. Journal of Verbal Learning and Verbal Behavior 8 (3): 323-342. http://dx.doi.org/10.1016/ S0022-5371(69)80124-6

Cegala, D. J., Marinelli, T. and Post, D. (2000) The effects of patient communication skills training on compliance. Arch Fam Med 9 (1): 57-64. http://dx.doi.org/10.1001/ archfami.9.1.57

Chesebro, J. J. and McCroskey, J. C. (2001) The relationship of teacher clarity and immediacy with student state receiver apprehension, affect, and cognitive learning. Communication Education 50 (1): 59-68. http://dx.doi. org/10.1080/03634520109379232

Ciske, D., Haavisto, A., Laxova, A., Rock, L. and Farrell, P. (2001) Genetic counseling and neonatal screening for cystic fibrosis: An assessment of the communication process. Pediatrics 107 (4): 699-705. http://dx.doi.org/ 10.1542/peds.107.4.699

Clever, S. L., Jin, L., Levinson, W. and Meltzer, D. O. (2008) Does doctor-patient communication affect patient satisfaction with hospital care? Results of an analysis with a novel instrument variable. HSR: Health Services Research 43 (5): 1505-1519. http://dx.doi.org/10.1111/ j.1475-6773.2008.00849.x

Coulehan, J. L. and Block, M. R. (2006) The Medical Interview: Mastering Skills for Clinical Practice (5th ed.). Philadelphia: F.A. Davis Co.

Deuster, L., Christopher, S. A., Donovan, J. and Farrell, M. H. (2008) A method to quantify residents' jargon use during counseling of standardized patients about cancer screening. Journal of General Internal Medicine 23 (12): 1947-1952. http://dx.doi.org/10.1007/s11606-0080729-3

DiMatteo, M. R., Hays, R. D. and Prince, L. M. (1986) Relationship of physicians' nonverbal communication skill to patient satisfaction, appointment noncompliance, and physician workload. Health Psychology 5 (6): 581-594. http://dx.doi.org/10.1037/0278-6133.5. 6.581

DuBois, N. F., Alverson, G. F. and Staley, R. K. (1979) Educational Psychology and Instructional Decisions. Homewood, Illinois: The Dorsey Press.

Elwyn, G., Gray, J. and Clarke, A. (2000) Shared decision making and non-directiveness in genetic counselling.

\section{equinoxonline}


Journal of Medical Genetics 37 (2): 135-138. http://dx. doi.org/10.1136/jmg.37.2.135

Farrell, M. H., Deuster, L., Donovan, J. and Christopher, S. (2008) Pediatric residents' use of jargon during counseling about newborn genetic screening results. Pediatrics 122 (2): 243-249. http://dx.doi.org/10.1542/peds.20072160

Farrell, M. H., Certain, L. and Farrell, P. M. (2001) Genetic counseling and risk communication services of newborn screening programs. Archives of Pediatrics and Adolescent Medicine 155 (2): 120-126.

Farrell, M. H., Chan, E. C. Y., Ladouceur, L. and Stein, J. M. (2009a) A structured implicit abstraction method to evaluate whether content of counseling before prostate cancer screening is consistent with recommendations by experts. Patient Education and Counseling 77 (3): 322-327. http://dx.doi.org/10.1016/j.pec.2009.09.023

Farrell, M. H., Christopher, S. A., Tluczek, A., KennedyParker, K., La Pean, A., Eskra, K. L., Collins, J., Hoffman, G., Panepinto, J. and Farrell, P. M. (2011) Early experience of the Wisconsin Project on improvement of communication process and outcomes after newborn screening. Wisconsin Medical Journal 110 (5): 221227.

Farrell, M. H. and Farrell, P. M. (2003) Newborn screening for cystic fibrosis: Ensuring more good than harm. Journal of Pediatrics 143 (6): 707-712. http://dx.doi. org/10.1016/j.jpeds.2003.09.022

Farrell, M. H. and Kuruvilla, P. (2008) Assessment of parental understanding by pediatric residents during counseling after newborn genetic screening. Archives of Pediatrics and Adolescent Medicine 162 (3): 199-204. http:// dx.doi.org/10.1016/j.jpeds.2003.09.022

Farrell, M. H., Kuruvilla, P., Eskra, K. L., Christopher, S. A. and Brienza, R. S. (2009b) A method to quantify and compare clinicians' assessments of patient understanding during counseling of standardized patients. Patient Education and Counseling 77: 128-135. http://dx.doi. org/10.1016/j.pec.2009.03.013

Farrell, M. H., La Pean, A. and Ladouceur, L. (2005) Content of communication by pediatric residents after newborn genetic screening. Pediatrics 116 (6): 1492-1498. http:// dx.doi.org/10.1542/peds.2004-2611

Farrell, M. H., Speiser, J., Deuster, L. and Christopher, S. A. (2012) Child health providers' precautionary discussion of emotions during communication about results of newborn genetic screening. Archives of Pediatrics and Adolescent Medicine 166 (1): 62-67. http://dx.doi.org/ 10.1001/archpediatrics.2011.696

Feinstein, A. (1985) Clinical Epidemiology: The Architecture of Clinical Research. Philadelphia: WB Saunders.

Fujishin, R. (2008) The Natural Speaker (6th edn). New York: Allyn \& Bacon.

Glanzer, M. and Cunitz, A. R. (1966) Two storage mechanisms in Free Recall. Journal of Verbal Learning and Verbal Behaviour 5 (4): 351-360. http://dx.doi.org/10. 1016/S0022-5371(66)80044-0

Greene, M. G., Adelman, R. D., Friedmann, E. and Charon, R. (1994) Older patient satisfaction with communication during an initial medical encounter. Social Science and Medicine 38 (9): 1279-1288. http:// dx.doi.org/10.1016/0277-9536(94)90191-0

Hall, J. A., Roter, D. L. and Katz, N. R. (1988). Meta-analysis of correlates of provider behavior in medical encounters. Medical Care 26 (7): 657-675. http://dx.doi.org/10. 1097/00005650-198807000-00002

Heritage, J. and Robinson, J. D. (2006) The structure of patients' presenting concerns: Physicians' opening questions. Health Communication 19 (2): 89-102. http://dx. doi.org/10.1207/s15327027hc1902_1

Inui, T. S., Yourtee, E. L. and Williamson, J. W. (1976) Improved outcomes in hypertension after physician tutorials: A controlled trial. Annals of Internal Medicine 84 (6): 646-651.

Jencks, S. F., Huff, E. D. and Cuerdon, T. (2003) Change in the quality of care delivered to medicare beneficiaries, 1998-1999 to 2000-2001. Journal of the American Medical Association 289 (3): 305-312. http://dx.doi. org/10.1001/jama.289.3.305

Kaplan, S. H., Greenfield, S. and Ware, J. E., Jr. (1989) Assessing the effects of physician-patient interactions on the outcomes of chronic disease. Medical Care 27 (3 Suppl): S110-127. http://dx.doi.org/10.1097/ 00005650-198903001-00010

Kurtz, S., Silverman, J. and Draper, J. (1998) Teaching and Learning Communication Skills in Medicine. Abingdon, Oxon, UK: Radcliffe Medical Press.

La Pean, A. and Farrell, M. H. (2005) Initially misleading communication of carrier results after newborn genetic screening. Pediatrics 116 (6): 1499-1505. http://dx.doi. org/10.1542/peds.2005-0449

Levinson, W. and Roter, D. (1993) The effects of two continuing medical education programs on communication skills of practicing primary care physicians. Journal of General Internal Medicine 8 (6): 318-324. http://dx.doi. org/10.1007/BF02600146

Ley, P. (1988) Communicating with Patients: Improving Communication, Satisfaction and Compliance. London: Croom Helm.

Ley, P., Bradshaw, P. W., Eaves, D. and Walker, C. M. (1973) A method for increasing patients' recall of information presented by doctors. Psychological Medicine 3 (2): 217220. http://dx.doi.org/10.1017/S0033291700048558

Lipkin, M., Putnam, S. and Lazare, A. (1995) The Medical Interview: Clinical Care, Education, and Research. New York: Springer. http://dx.doi.org/10.1007/978-14612-2488-4

Lucas, S. (2001) The Art of Public Speaking (8th edn). Boston: McGraw Hill.

Mainz, J. (2003) Defining and classifying clinical indicators for quality improvement. International Journal for Quality Health Care 15 (6): 523-530. http://dx.doi. org/10.1093/intqhc/mzg081

Makoul, G. (2001) Essential elements of communication in medical encounters: The Kalamazoo consensus statement. Academic Medicine 76 (4): 390-393. http://dx.doi. org/10.1097/00001888-200104000-00021 
Marvel, M. K., Epstein, R. M., Flowers, K. and Beckman, H. B. (1999) Soliciting the patient's agenda: Have we improved? Journal of the American Medical Associaiton 281 (3): 283-287. http://dx.doi.org/10.1001/jama.281. 3.283

Maynard, D. W. (1996) On 'realization' in everyday life: The forecasting of bad news as a social relation. American Sociological Review 61 (1): 109-131. http://dx.doi.org/ $10.2307 / 2096409$

Miller, G. E. (1990) The assessment of clinical skills/competence/performance. Academic Medicine 65 (9 Suppl): S63-67. http://dx.doi.org/10.1097/00001888-19 9009000-00045

Morgan, M., Fischhoff, B., Bostrom, A. and Atman, C. (eds) (2001) Risk Communication: A Mental Models Approach. Cambridge: Cambridge University Press. http:// dx.doi.org/10.1017/CBO9780511814679

Ong, L. M., de Haes, J. C., Hoos, A. M. and Lammes, F. B. (1995) Doctor-patient communication: A review of the literature. Social Science Medicine 40 (7): 903-918. http://dx.doi.org/10.1016/0277-9536(94)00155-M

Orth, J. E., Stiles, W. B., Scherwitz, L., Hennrikus, D. and Vallbona, C. (1987) Patient exposition and provider explanation in routine interviews and hypertensive patients' blood pressure control. Health Psychology 6 (1): 29-42. http://dx.doi.org/10.1037/0278-6133. 6.1 .29

Rhoades, D. R., McFarland, K. F., Finch, W. H. and Johnson, A. O. (2001) Speaking and interruptions during primary care office visits. Family Medicine 33 (7): 528-532.

Robbins, J. A., Bertakis, K. D., Helms, L. J., Azari, R., Callahan, E. J. and Creten, D. A. (1993) The influence of physician practice behaviors on patient satisfaction. Family Medicine 25 (1): 17-20.

Rost, K. M., Flavin, K. S., Cole, K. and McGill, J. B. (1991) Change in metabolic control and functional status after hospitalization. Impact of patient activation intervention in diabetic patients. Diabetes Care 14 (10): 881889. http://dx.doi.org/10.2337/diacare.14.10.881

Roter, D. L. and Hall, J. A. (eds) (1992) Doctors Talking with Patients, Patients Talking with Doctors: Improving Communication in Medical Visits. Westport, Connecticut: Auburn House.

Seel, N. (2006) Mental models in learning situations. Advances in Psychology 138: 85-110. http://dx.doi.org/ 10.1016/S0166-4115(06)80028-2

Sharp Jr., H. and McClung, T. (1966) Effects of organization on the speaker's ethos. Speech Monographs 33: 182-183. http://dx.doi.org/10.1080/03637756609375495

Silverman, J., Kurtz, S. and Draper, J. (eds) (1998) Skills for Communicating with Patients. Abingdon, Oxon, UK: Radcliffe Medical Press.

Smith, R. C. (ed) (2002) Patient-Centered Interviewing: An Evidence-Based Method (2nd edn). Philadelphia: Lippincott, Williams and Wilkins.

Stewart, M., Brown, J. B., Donner, A., McWhinney, I. R., Oates, J., Weston, W. W. and Jordan, J. (2000) The impact of patient-centered care on outcomes. Journal of Family Practice 49 (9): 796-804.
Street Jr, R. L. (1991) Physicians' communication and parents' evaluations of pediatric consultations. Medical Care 29 (11): 1146-1152. http://dx.doi.org/10.1097/ 00005650-199111000-00006

Thompson, E. C. (1960) An experimental investigation of the relative effectiveness of organizational structure in oral communication. Southern Speech Journal 26: 5969. http://dx.doi.org/10.1080/10417946009371589

Titsworth, B. S. (2001) The effects teacher immediacy, use of organizational lecture cues, and students' notetaking on cognitive learning. Communication Education 50 (4): 283-297.http://dx.doi.org/10.1080/03634520109379256

Stephanie Christopher received her MA in Communication from Marquette University and is currently a Research Lab Supervisor in the Center for Patient Care and Outcomes Research at the Medical College of Wisconsin and an adjunct communication instructor at Marquette University. Her research interests include examining the barriers to effective interpersonal communication between physicians and patients. Address for correspondence: PCOR, Medical College of Wisconsin, 8701 Watertown Plank Road, Milwaukee, WI, USA. Email: schristopher@mcw.edu

Nadia Ahmad received her PhD in Psychology from the University of Kansas and is currently a Research Fellow in the Department of Family and Community Medicine at the Medical College of Wisconsin. Her research interests include the influence of interpersonal dynamics on health care. Address for correspondence: Department of Family and Community Medicine, Medical College of Wisconsin, 8701 Watertown Plank Road, Milwaukee, WI, USA. Email: nahmad@mcw.edu

Lisa Bradford received her $\mathrm{PhD}$ in Communication from Arizona State University and is currently a post-doctoral fellow and instructor at the Medical College of Wisconsin. Her research interests include patient-provider communication in challenging health contexts including helping moms and young families navigate the complex medical system. Address for correspondence: PCOR, Medical College of Wisconsin, 8701 Watertown Plank Road, Milwaukee, WI, USA. Email: lbradford@mcw.edu

Jenelle Collins received her BSN-RN from the University of Kansas and is currently a Clinical Research Coordinator in the Center for Patient Care and Outcomes Research at the Medical College of Wisconsin. Her research interests include methods for improving parent education through patient-centered health communication and psychosocial outcomes related to physician communication. Address for correspondence: PCOR, Medical College of Wisconsin, 8701 Watertown Plank Road, Milwaukee, WI, USA. Email: jlcollins@mcw.edu

Kerry Eskra received her BBA from the University of Wisconsin-Milwaukee and recently completed her MS in

\section{eevinoxonline}


rehabilitation counseling from the University of WisconsinMadison. Her research interests include the intersection of psychology and communication research. Address for correspondence: PCOR, Medical College of Wisconsin, 8701 Watertown Plank Road, Milwaukee, WI, USA. Email: kleskra@gmail.com

Alison La Pean Kirschner received her MS in genetic counseling from Northwestern University and is currently a certified genetic counselor in the Center for Patient Care and Outcomes Research at the Medical College of Wisconsin. Her research interests include newborn screening, qualitative analysis of patient interviews, and assessing psychosocial outcomes of communication and counseling. Address for correspondence: PCOR, Medical College of Wisconsin, 8701 Watertown Plank Road, Milwaukee, WI, USA.Email: alapean@mcw.edu

Faith O'Tool received her BS in Communication Arts from University of Wisconsin-Madison and is currently a program coordinator in the Center for Patient Care and Outcomes Research at the Medical College of Wisconsin. Her research interests include improving communication between physicians and families. Address for correspond- ence: PCOR, Medical College of Wisconsin, 8701 Watertown Plank Road, Milwaukee, WI, USA. Email: fotool@ mcw.edu

Sara Roedl received her PhD in Mass Communication from Southern Illinois University and is a communication researcher in the Center for Patient Care and Outcomes Research at the Medical College of Wisconsin. Her research interests include the relationship between mass media messages and public health priorities. Address for correspondence: PCOR, Medical College of Wisconsin, 8701 Watertown Plank Road, Milwaukee, WI, USA. Email: sroedl@mcw.edu

Michael H. Farrell received his MD from St. Louis University School of Medicine and was a Robert Wood Johnson Clinical Scholar at the University of Michigan. He is currently an Associate Professor at the Medical College of Wisconsin. He is a primary care internist and pediatrician who has built his teaching and research career on exploring ways to improve the quality of communication between clinicians and patients. Address for correspondence: PCOR, Medical College of Wisconsin, 8701 Watertown Plank Road, Milwaukee, WI, USA. Email: mfarrell@mcw.edu 
Reproduced with permission of the copyright owner. Further reproduction prohibited without permission. 